\title{
Crecimiento de placa de ateroma en arteria carótida de paciente específico según diferentes estímulos mecánicos
}

Patricia Hernández López ${ }^{1}$, Myriam Cilla Hernández ${ }^{1,2,3}$, Miguel Ángel Martínez ${ }^{1,3}$ Barca, Estefanía Peña Baquedano ${ }^{1,3}$

${ }^{1}$ Applied Mechanics and Bioengineering (AMB) Universidad de Zaragoza, Mariano Esquillor s/n, 50018, Zaragoza, Spain.

${ }^{2}$ Centro Universitario de la Defensa. Academia General Militar, Zaragoza, Spain Instituto de Investigación en Ingeniería de Aragón (I3A)Ｔel. +34-976762707,e-mail: phernand@unizar.

\section{Motivación}

Aterosclerosis $=$ Millones de muertes anualmente

Formación de placas de ateroma

Por alta concentración de colesterol en sangre (LDL)

Infartos, ictus, isquemias

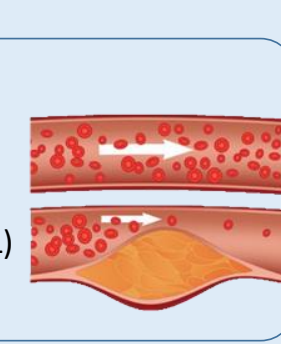

\section{Objetivo}

Modelo computacional - Paciente específico arteria carótida Predecir crecimiento de placas de ateroma Validación del modelo con las carótidas reales

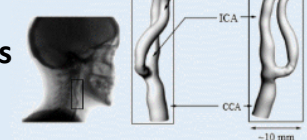

\section{Estímulos mecánicos}

Cambian forma de células endoteliales Time Average Wall Shear Stress (TAWSS

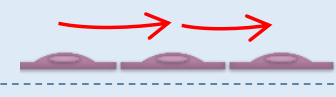

Oscillatory Shear Index (OSI)

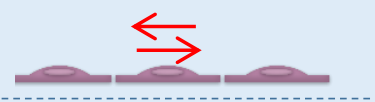

Nueva variable propuesta (NV)

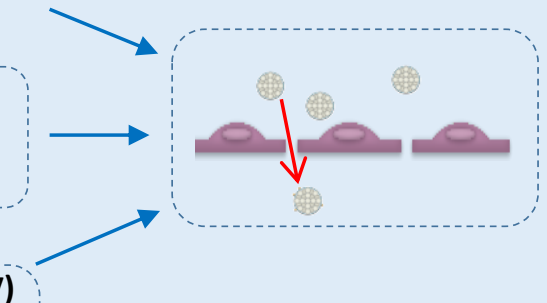

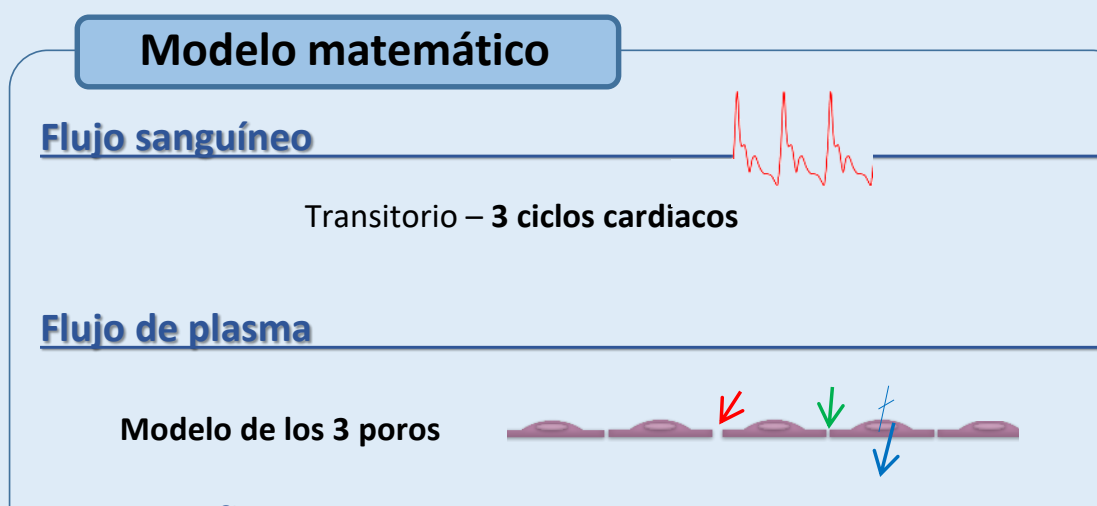

Proceso inflamatorio

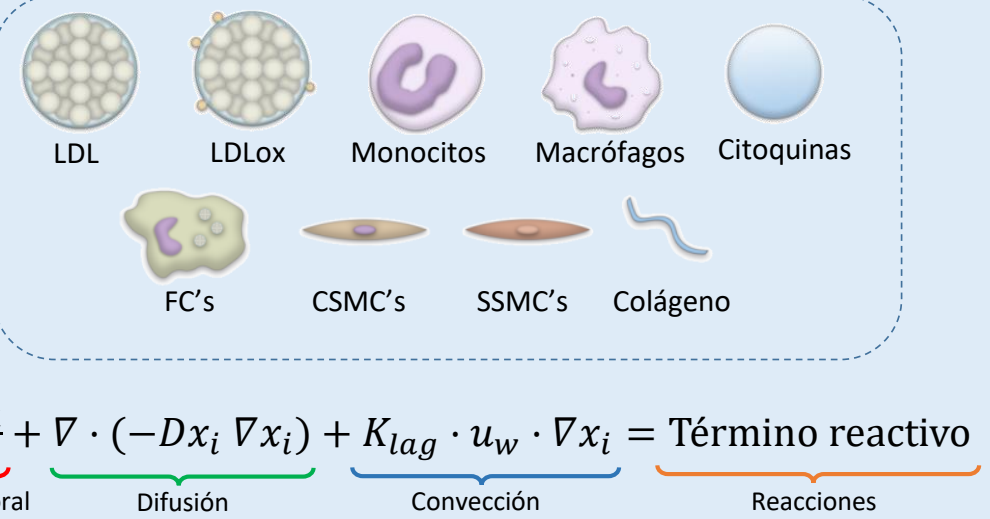

Crecimiento

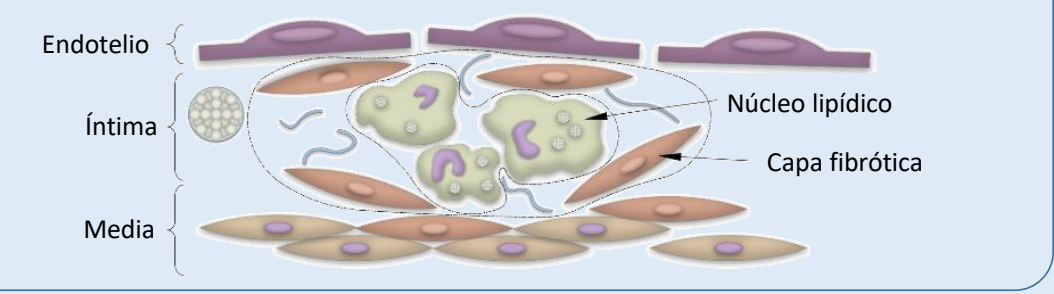

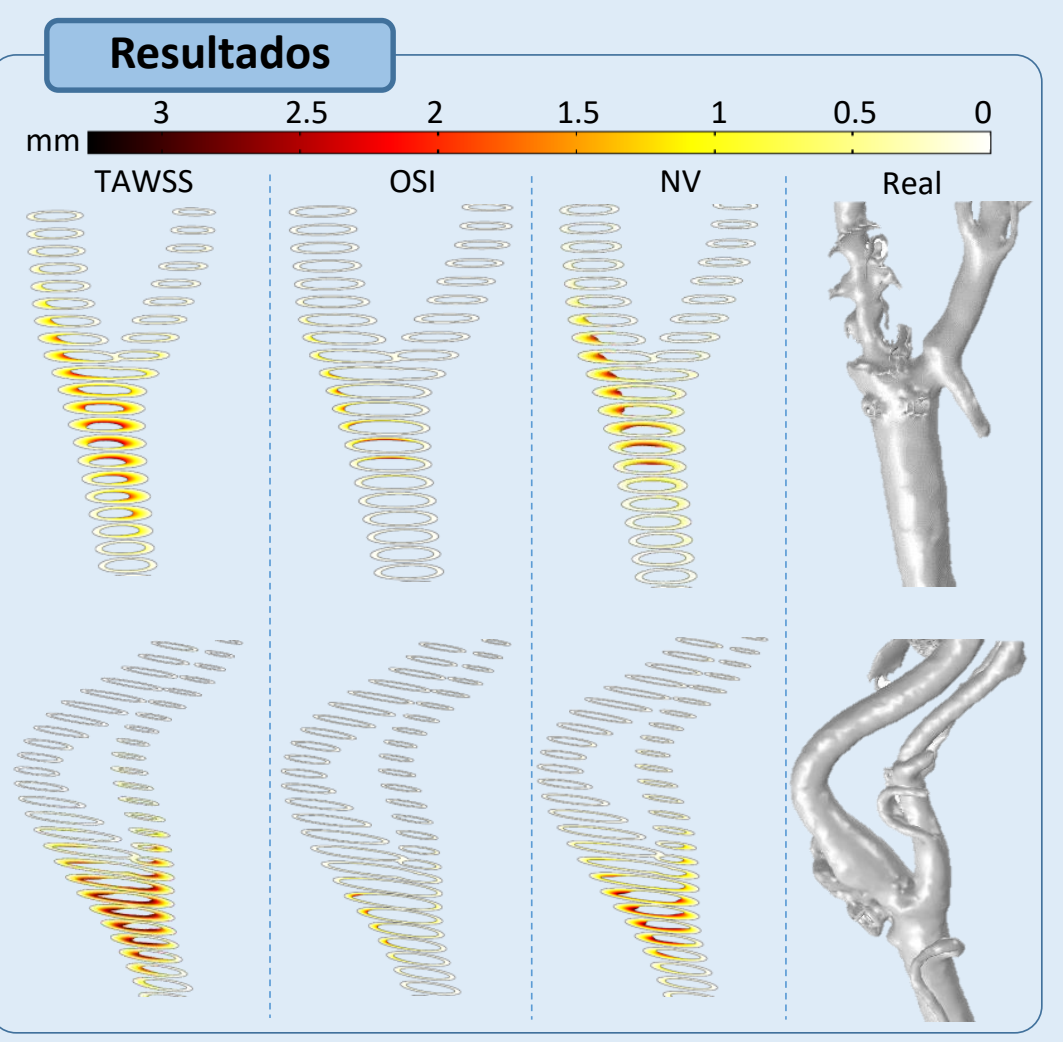

Conclusiones

$\checkmark$ Modelo validado con carótidas reales

Modelo predice las zonas de crecimiento de placa de ateroma

\section{Referencias}

I] Cilla M., Peña E. and Martinez M. A. Effect of transmural transport properties on ateroma plaque formation and development. Annals of Biomedical Engineering, 43(7):1516-30, 2015.

[2] OIgac U., Kurtcuoglu V. and Poulikakos D. Computational modeling of coupled blood-wall mas transport of LDL: Effects of local wall shear stress. American Journal of Physiology-Heart and 